\title{
Insulin Acts as Stimulatory Agent in Diabetes-Related Escherichia Coli Pathogenesis
}

\author{
Kamelija Madacki-Todorović1, Izet Eminovićn ${ }^{2}$, Nadira Ibrišimović Mehmedinović ${ }^{3}$ and \\ Mirza Ibrišimovićc ${ }^{*}$
}

${ }^{1}$ Sarajevo Medical School, University Sarajevo School of Science and Technology, Bosnia and Herzegovina

${ }^{2}$ Faculty of Natural Science and Mathematics, University Sarajevo, Bosnia and Herzegovina

${ }^{3}$ Faculty of Natural Science and Mathematics, University Tuzla, Bosnia and Herzegovina

*Corresponding author: Mirza Ibrišimović, Sarajevo Medical School, University Sarajevo School of Science and Technology, Hrasnička cesta 3a, 71000 Sarajevo, Bosnia and Herzegovina, Tel: +387-33-975-042, Fax: +387-33-975-030

\begin{abstract}
Background: In general, diabetic patients are more prone to microbial infections, which is believed to be caused due to high glucose levels in blood which compromise components of the immune system. However, it is little known about role of therapeutic insulin administration on dissemination of infectious diseases in people with diabetes mellitus.

Methods: The study included the clinically isolated strains of Escherichia coli (E. coli) with biofilm forming capacity as well as referent non-biofilm former $E$. coli strain as control. Metabolic activity, level of virulence and biofilm forming capacity of tested $E$. coli strains were investigated in vitro conditions under presence of human hormone insulin at different incubation time points.

Results: Administration of hormone insulin in concentration of $2.5 \mathrm{U} / \mathrm{ml}$ resulted in significant increase in proliferation of all tested $E$. coli strains under in vitro conditions at 37 ${ }^{\circ} \mathrm{C}$. Presence of insulin also stimulated expression of $E$. coli virulent factor enzyme aspartyl proteinase, which in synergism with human insulin served as signal molecules for bacterial quorum sensing and biofilm formation.

Conclusion: Results of this study present first report about direct effect of hormone insulin on elevated metabolic activity of $E$. coli in a linkage with its biofilm forming capability. This opens a new look at understanding the cause of various bacterial infections in diabetic patients, as well as their multi-resistance to antibiotics that occurs due to changed bacterial metabolism and their newly acquired colonization abilities.
\end{abstract}

\section{Keywords}

Insulin, Diabetes, E. coli, Aspartyl proteinase, Biofilm

\section{Introduction}

Pathogenic microorganisms may be of different strains, which are most prevalent in bacteria and can cause disease due to supression of the host immune mechanisms. The patients with diabetes mellitus are at high risk for developing severe and life threatening microbial infections [1-4]. One of the most common pathogen in diabetic patients that can affect all organs and systems is Escherichia coli (E. coli). E. coli is causative agent in $70 \%$ cases of diabetic patients with an emphysematous urinary tract infections and in $40 \%$ of all diabetic patients with emphysematous cholecystitis $[5,6]$. Many studies showed that the reason for diabetic patients to be more prone to microbial infections is in hyperglycemic physiological status they have, and which has negative effect on phagocytic function $[7,8]$. As we already know, any microbe which can cause systemic infection is exposed to different host factors. These factors can be different therapeutic agents especially in case of chronic diseases, including hormone insulin which is administered to patients with diabetes mellitus. Some previous studies already established that human insulin stimulates $E$. coli growth and its ability to form a biofilm [9-11]. However, besides its ability to affect growth kinetic of $E$. coli, not much is known about other effects of insulin on $E$. coli in course of systemic infection, and there is lack of data on how insulin may affect metabolic activity of this pathogen and its ability

Citation: Madacki-Todorović K, Eminović I, Mehmedinović NI, Ibrišimović M (2018) Insulin Acts as Stimulatory Agent in Diabetes-Related Escherichia Coli Pathogenesis. Int J Diabetes Clin Res 5:098. doi. org/10.23937/2377-3634/1410098

Accepted: December 03, 2018: Published: December 05, 2018

Copyright: (C) 2018 Madacki-Todorović K, et al. This is an open-access article distributed under the terms of the Creative Commons Attribution License, which permits unrestricted use, distribution, and reproduction in any medium, provided the original author and source are credited. 
to become a biofilm former. The aim of this study was to examine the effect of hormone insulin on expression of enzymatic virulent factors of $E$. coli as the most common pathogen associated with morbimortality in diabetic patients.

\section{Methods}

\section{Strains and growth conditions}

Three strains of E. coli (E. coli-C1, E. coli-C2 and E. co(i-C3) with strong biofilm forming ability were isolated from clinical samples of hospitalized patients suffering from urinary tract infections by using conventional microbiological identification and isolation methods (based on colony morphology on blood and MacConkey agar). The culture samples of all three $E$. coli cultures were growing up to $10^{6}$ and $10^{7} \mathrm{CFU}$ on blood agar. A species identification was performed using standardized biochemical tests, including antibiotic sensitivity tests (Bauer-Kirby test). One E. coli (E. coli-Ref) strain without ability to form biofilms was used as reference and included as control in all performed experiments. Control strains cultured in absence of insulin were also involved in the study as the negative control. All tested bacteria were growing in trypticase soy broth (TSB) media, supplemented with $1 \%$ glucose, under aerobic conditions.

\section{Generation of growth curve}

A $10 \mu$ l of over-night culture from all four E. colistrains, were inoculated in $3 \mathrm{ml}$ of TSB growth media in a sterile, plastic $15 \mathrm{ml}$ tubes. The cultures where growing at $37^{\circ} \mathrm{C}$ at different incubation times: $0 \mathrm{~h}, 6 \mathrm{~h}, 12 \mathrm{~h}, 18 \mathrm{~h}$ and 24 h. Before incubation, each test tube containing $E$. coli cells was supplemented with human hormone insulin (Sigma-Aldrich) in dosing concentration of $2.5 \mathrm{U} / \mathrm{ml}$. Each test sample was measured by spectrophotometer for its optical density at wave length of $600 \mathrm{~nm}$.

\section{Sample preparation and aspartyl proteinase assay}

After incubation, $0.5 \mathrm{ml}$ of bacterial culture was mixed with $2 \mathrm{ml}$ of $1 \%$ bovine serum albumin (BSA), and incubated at $37{ }^{\circ} \mathrm{C}$ for 30 minutes. The reaction was stopped by adding $5 \mathrm{ml}$ of $10 \%$ trifluoroacetic acid. After this, the samples were centrifuged for 10 minutes at $1000 \mathrm{rpm}$ and aspartyl proteinase concentration was determined. $1 \% \mathrm{BSA}$ and $10 \%$ trifluoroacetic acid were diluted in $0.1 \mathrm{M}$ citrate buffer ( $\mathrm{pH} 3.5)$.

\section{Determination of $E$. coli metabolic activity}

Aspartyl proteinase concentration was determined by using spectrophotometer and measuring absorbance of the test samples at $260 \mathrm{~nm}$ and $280 \mathrm{~nm}$ (according to Warburg (hristian). The final calculations are performed by the following equation: $\mathrm{mg}$ of Protein $/ \mathrm{mL}=1.55 \times$ $A_{280}-0.76 \times A_{260}$.

\section{Testing of biofilm forming capacity}

Test tubes with $E$. coli cells whose growth was stopped after different incubation times (after $0 \mathrm{~h}, 6 \mathrm{~h}$, $12 \mathrm{~h}, 18 \mathrm{~h}$ and $24 \mathrm{~h}$ ) were exempt from growing culture and washed with phosphate buffered saline (PBS) with $\mathrm{pH}$ 7.5. After that, tubes were turned upside down to dry for about 20 minutes and then $1 \mathrm{ml}$ of $0.1 \%$ crystal violet was added. It was important to make sure that crystal violet comes in contact with all cells being attached on the plastic walls of the test tube. After incubation of 5 minutes, the crystal violet stain was washed with $\mathrm{ddH}_{2} \mathrm{O}$, and test tubes were inspected for biofilm formation. Only the tubes with visible violet film lining the walls of tube were considered as positive for biofilm formation and based on darkness of the film and number of cells, were categorized as weak, moderate and strong [12].

\section{Statistical analysis}

Presented data are expressed as mean \pm standard deviation (SD). For analysis of datasets Student's t-test and one-way ANOVA (corrected with Bonferroni's posthoc test) were applied. A p-value less than 0.05 was considered statistically significant.

\section{Results}

\section{E. coli proliferation was significantly increased due to insulin administration under in vitro conditions}

One of the most important characteristics of microorganisms including $E$. coli is their ability to grow and multiply in different environments if they have all necessary nutritive supplements. We investigated growth of three $E$. coli strains which were isolated from clinical specimens (E. coli-C1, E. coli-C2 and E. coli-C3) and turned out to be strong biofilm formers, together with non-biofilm former E. coli strain (E. coli$R e f)$ as the control. After addition of human insulin in dosing concentration of $2.5 \mathrm{U} / \mathrm{ml}$, all $E$. coli strains were incubated in growth media at $37{ }^{\circ} \mathrm{C}$ for different incubation times $(0 \mathrm{~h}, 6 \mathrm{~h}, 12 \mathrm{~h}, 18 \mathrm{~h}$ and $24 \mathrm{~h})$. The culture samples of $1 \mathrm{ml}$ were pooled out after defined incubation times and optical density at $600 \mathrm{~nm}$ wave length was measured. Insulin administration had significant stimulatory effect on $E$. coli proliferation in vitro for all four tested E. coli bacterial strains, when compared with control strains which were not supplemented with insulin and showed notably lower proliferation rate at all incubation time points (Figure 1).

Logarithmic phase of $E$. coli growth under presence of human insulin was clearly established after $6 \mathrm{~h}$ of incubation and significantly greater than in the negative control: $30.4 \%$ for E. coli-C1, $22.4 \%$ for E. coli-C2, $29.7 \%$ for E. coli-C3 and 17.5\% for E. coli-Ref (Figure 1A, Figure $1 \mathrm{~B}$, Figure $1 \mathrm{C}$ and Figure 1D). Human hormone insulin at concentration of $2.5 \mathrm{U} / \mathrm{ml}$ strongly enhanced the $E$. coli proliferation for all tested bacterial strains, serving as stimulatory agent for $E$. coli cell reproduction. 

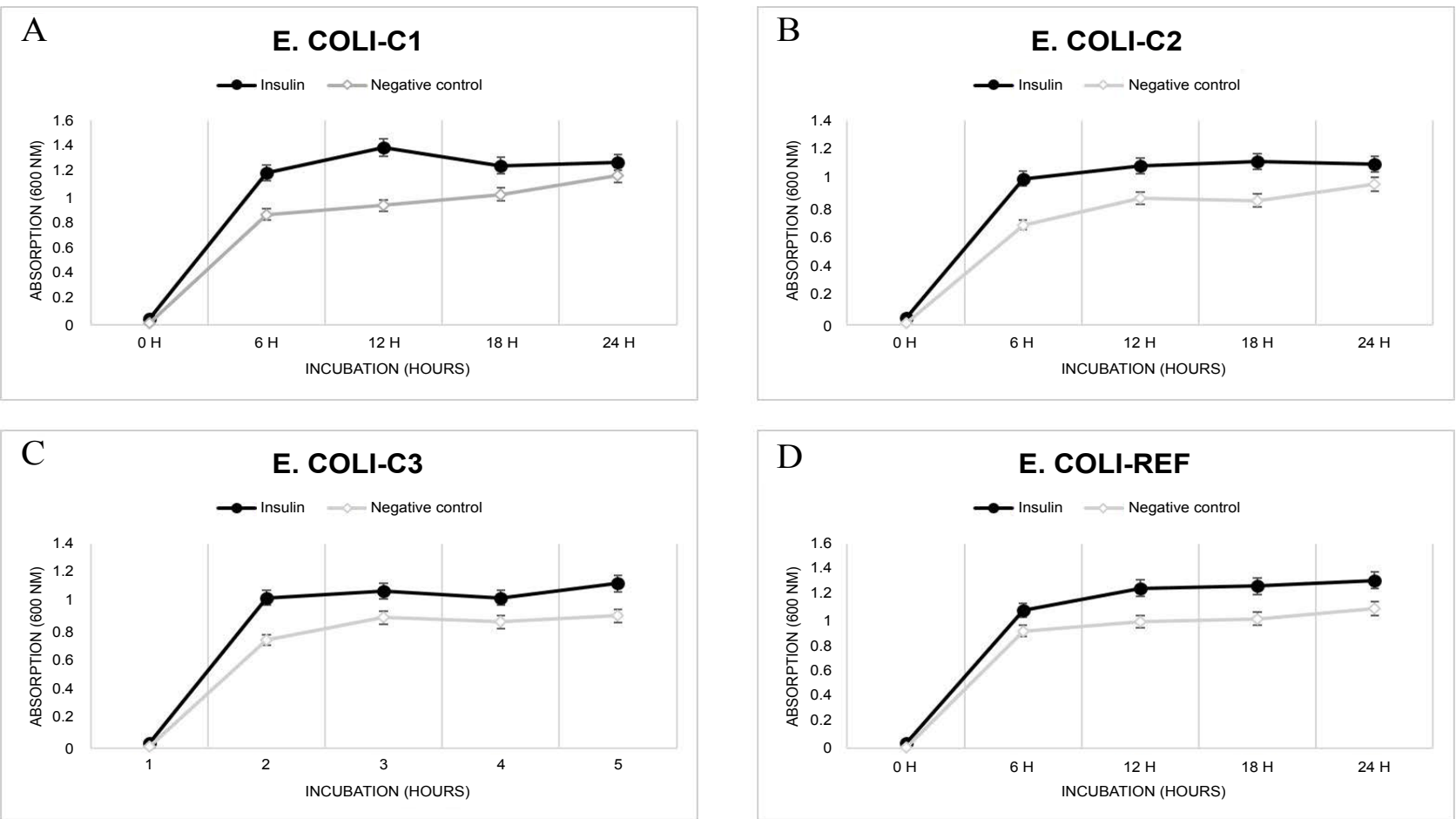

$\mathrm{D}$

E. COLI-REF

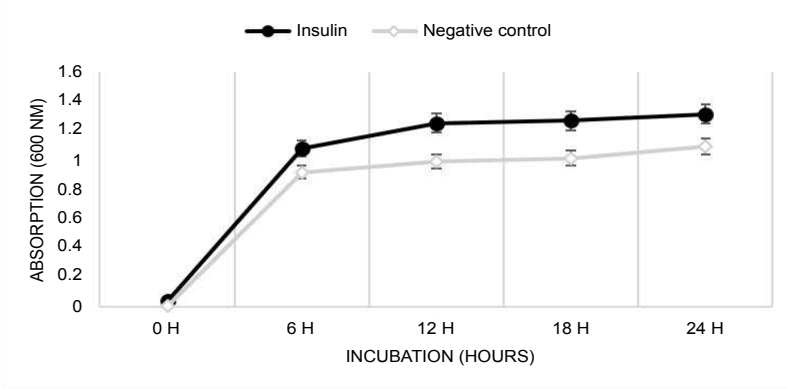

Figure 1: Effect of insulin on E. coli proliferation in vitro (mean $\pm S D, n=3$ ).
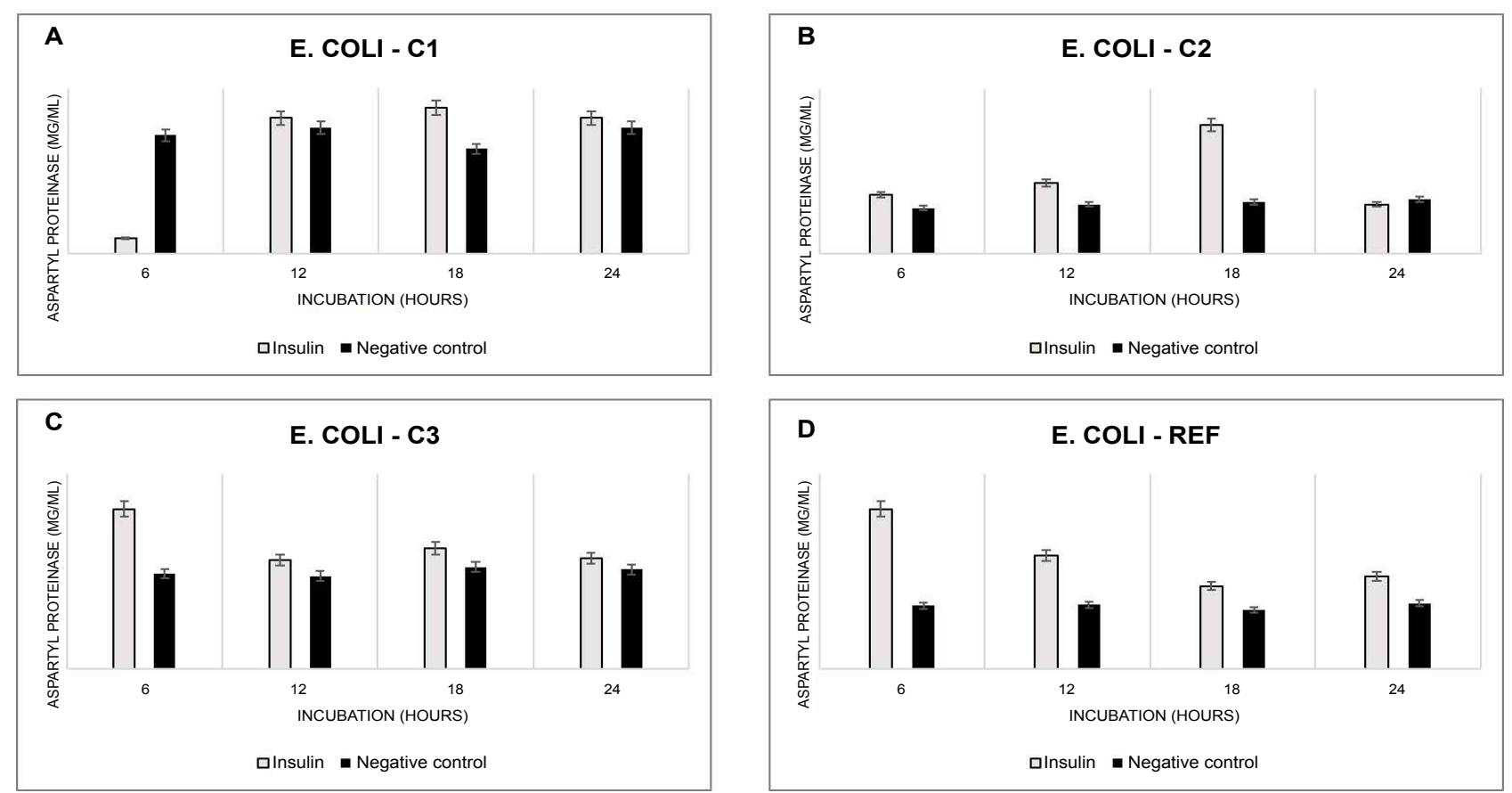

Figure 2: Excretion of enzyme aspartyl proteinase from different $E$. coli strains after treatment with insulin. In case of the negative control (black bars) addition of insulin was excluded (mean $\pm S D, n=3,{ }^{* * *} p<0.001,{ }^{* *} p<0.01,{ }^{*} p<0.05$ ).

Insulin-dependent excretion of bacterial aspartyl proteinase elevated the virulence state of $E$. coli

Microbial proteases play vital role in cell viability and virulence status of the microbe and protease genes are new potential therapeutic targets in treatment of infectious diseases [13]. Aspartyl proteinase of $E$. coli is catalytic type of enzyme which is released from the cell at higher concentration during infection process of the host. Here we describe the effect of human insulin on aspartyl proteinase excretion which was stimulatory in all tested $E$. coli strains. Administration of hormone insulin in dosing concentration of $2.5 \mathrm{U} / \mathrm{ml}$ showed significant stimulatory effect on metabolic activity of $E$. coli isolates as well as for $E$. coli referent strain (Figure 2). The levels of virulent aspartyl proteinase enzymes were notably elevated during logarithmic and stationary phase of bacterial growth when compared with control strains that were not supplemented with insulin. E. coli-C1 and E. coli-C2 strains showed significant increase in aspartyl proteinase excretion, especially after 18 hours of incubation in growth media at $37^{\circ} \mathrm{C}$, where detected increase was for 1.38 fold 

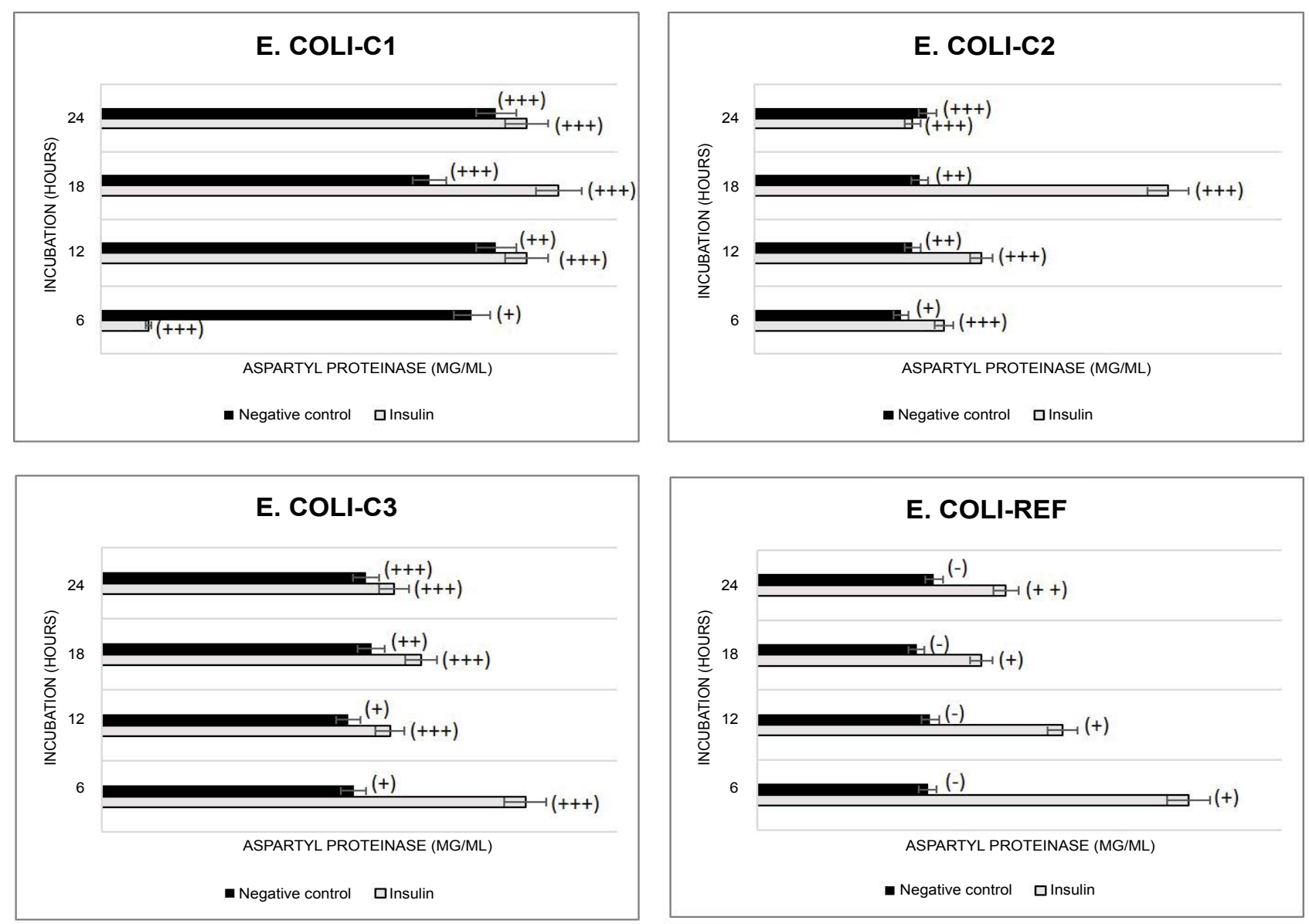

(-) no biofilm; (+) weak biofilm; (++) moderate biofilm; (+++) strong biofilm

Figure 3: Synergism between amount of excreted aspartyl proteinase as $E$. coli virulent factor and its biofilm forming capacity (mean $\pm \mathrm{SD}, \mathrm{n}=3$ ).

for E. coli-C1 and 2.36 fold for E. coli-C2.

Interestingly, the elevated levels of aspartyl proteinase in case of E. coli-C3 and in E. coli-Ref were observed much earlier, after only 6 hours of incubation, while the levels of excreted enzyme in absence of human insulin stayed constant in negative control strain (without insulin supplement) for all incubation time points (Figure 2). After only 6 hours of incubation there was 1.7 fold increase in aspartyl proteinase enzyme secretion for $E$. coli-C3 and 2.54 fold increase for E. coli-Ref (Figure 2C and Figure 2D). This findings identified human insulin as potential risk factor for dissemination of $E$. coli infections and increase of related pathogenicity due to its stimulatory effect on expression of aspartyl proteinase genes. Since the aspartyl proteinase amount was greater in E. coli-Ref strain, which we know that do not form the biofilm under absence of insulin, we may conclude that bacterial cells increase amount of aspartyl proteinase excretion as necessary signal molecule that will initiate biofilm formation or strengthen already existing $E$. coli biofilm former such as in the case of E. coli-C3 strain (Figure 2).

Insulin may serve as the key signal molecule in process of biofilm formation in patients with diabetes mellitus

A multi-drug resistant bacteria with biofilm
Table 1: Biofilm formation after insulin addition in concentration of $2.5 \mathrm{U} / \mathrm{mL}$ for different incubation times.

\begin{tabular}{|l|l|l|l|l|l|}
\hline Biofilm formation & $0 \mathrm{~h}$ & $6 \mathrm{~h}$ & $12 \mathrm{~h}$ & $18 \mathrm{~h}$ & $24 \mathrm{~h}$ \\
\hline E. coli Strain & - & +++ & +++ & +++ & +++ \\
\hline E. coli-C1 & - & + & ++ & +++ & +++ \\
\hline Negative control-C1 & - & +++ & +++ & +++ & +++ \\
\hline E. coli-C2 & - & + & ++ & ++ & +++ \\
\hline Negative control-C2 & - & +++ & +++ & +++ & +++ \\
\hline E. coli-C3 & - & + & + & ++ & +++ \\
\hline Negative control-C3 & - & + & + & + & ++ \\
\hline E. coli-Ref & - & - & - & - & - \\
\hline Negative control-Ref & & & & \\
\hline
\end{tabular}

(-) no biofilm; (+) weak biofilm; (++) moderate biofilm; $(+++)$ strong biofilm.

forming capacity are reason of common devastating complications of diabetes, including diabetic foot ulcer and diabetic foot infections [14]. Besides Staphylococcus aureus and Pseudomonas aeruginosa, E. coli is also leading microbe with biofilm forming ability especially in diabetic patients with urinary tract infection [15]. During our study we investigated role of human insulin as signaling molecule for expression of virulence factors and biofilm formation in different $E$. coli specimens. In other words, we tested ability of insulin to act as autoinducer in dissemination of $E$. coli infection and pathogenicity. Results show that in all tested clinical isolates of $E$. coli, including referent $E$. coli strain, there 
was stimulatory effect of insulin on expression of virulence factors in $E$. coli and biofilm formation. After only six hours of incubation after addition of hormone insulin in dosing concentration of $2.5 \mathrm{U} / \mathrm{ml}$ there was significant increase in biofilm formation capacity, from weak to strong biofilm formation when compared with negative control E. coli strains which were not supplemented with insulin (Table 1).

The similar results were observed for all three clinical species of E. coli. Especially interesting findings were in case of referent $E$. coli strain which was not capable of forming biofilm in absence of insulin. However, after insulin addition, after only 6 hours of incubation, there was clear biofilm formation which became stronger with longer incubation time, starting with weak biofilm formation after 6 hours of incubation to moderate after 24 hours of incubation in growth media, at $37^{\circ} \mathrm{C}$ (Table 1 ).

\section{Synergistic effect of insulin and aspartyl proteinase was stimulatory for quorum sensing in $E$. coli}

Process of quorum sensing enables microbes to express environmentally dependent processes with a goal of maximization of virulent status [16]. Bacteria and other microbes communicate through signaling pathways which are still not completely understood, especially in case of biofilm formation and development of antibiotic resistance. In course of our study it was possible to see that excreted amount of enzyme aspartyl proteinase was pretty constant for negative control E. coli strain (not supplemented with insulin) for all tested incubation time points, and that there was drastic increase in amount of enzyme aspartyl proteinase after addition of insulin (Figure 3 ). It was also possible to notice that clinically isolated $E$. coli strains showed greater ability for biofilm formation which was more observable in case of higher aspartyl proteinase expression after only 6 hours of incubation (Figure 3C), and especially after 18 hours of incubation at $37{ }^{\circ} \mathrm{C}$ (Figure $3 \mathrm{~A}$ and Figure $3 \mathrm{~B}$ ). Obvious synergism between excreted amount of aspartyl proteinase and biofilm formation ability was observable in case of referent $E$. coli strain which acted as non-biofilm former, before including in experiments with insulin. After addition of insulin in dosing concentration of $2.5 \mathrm{U} / \mathrm{ml}$, generation of biofilm layer after only six hours of incubation could be clearly recognized (Figure 3D).

\section{Discussion}

Escherichia coli is one of the main pathological agents causing high frequency of invasive infections in diabetic patients $[4,15,17]$. This pathogen, similarly to any other microorganism that can cause systemic infection, is exposed to various host factors including hormone insulin. Though there are some reports on direct effect of glucose concentration on microbial biofilm formation [18], there is still lack of data about insulin as potential risk factor for increased $E$. coli virulence. Insulin concentrations in patient's urine or blood can be various de- pending from insulin dosing and frequency of its administration. Dose of regular insulin for adults is in range $5-10 \mathrm{U} / \mathrm{ml}$, also lower for young patients or even higher for other diabetic patients depending from their clinical status. In our study we included insulin concentration that responds to $2.5 \mathrm{U} / \mathrm{ml}$ which is half of the dosage for adults. Our study showed that human hormone insulin, even in this low concentration, not only had significant stimulatory effect on proliferation of bacterial cells, but also significantly affected metabolic activity of $E$. coli and acted as an autoinducer for biofilm formation (Figure 1, Figure 2 and Figure 3). These findings suggest that human insulin is able to modulate expression of virulent factors including enzyme aspartyl proteinase which excretion was notably elevated in presence of insulin (Figure 2). We know that higher frequency of infections in patients with diabetes mellitus is caused by the hyperglycemic environment that negatively impairs immune response of the host [1-5]. However, based on these findings, we can justifiably assume that insulin treatment can also help dissemination of $E$. coli infection in diabetic patients, since this can trigger expression of enzyme aspartyl proteinase as the virulent factor that can further act as signal molecule for quorum sensing and biofilm formation, which, in general, can be the reason for requirement of greater number of medical interventations in patients with diabetes mellitus. Changes in E. coli metabolism may also be the reason for often nosocomial infections which are mainly associated with this bacterial pathogen [19]. Essential for the survival and growth of $E$. coli is its biofilm formation ability that leads to multi-antibiotic resistance. Since individuals with type 2 diabetes mellitus can excrete insulin (or/ and glucose) in their urine, this can be the reason for increased incidence of severe urinary tract infections in these medical conditions. However, material type from which the urine catheters are made, can also be of crucial importance if $E$. coli can freely attach to it and form the biofilm [10]. This feature together with insulin presence can lead to fruitful environment for biofilm development. Results of this study also underline the need for development of alternative catheter materials that will not allow biofilm formation and guidelines in choice of catheters for diabetic patients. Obtained results also emphasize the need to explore other therapeutics and hormones besides insulin that affect glucose levels in the body such as prednisone and cortisone, and the effect they could have on metabolic activity of $E$. coli and its biofilm forming ability. Due to the fact that $E$. coli strains may differ in their virulence traits [20], it is extremely important to detect the further agents, besides insulin, which contribute to elevation of microbial pathogenicity, especially common in case of immunodeficiency and risk groups such as diabetic patients.

\section{Conflict of Interests}

The authors declare that they have no conflict of interest. 


\section{References}

1. Casqueiro J, Casqueiro J, Alves C (2012) Infections in patients with diabetes mellitus: A review of pathogenesis. Indian J Endocrinol Metab 16: S27-S36.

2. Peleg AY, Weerarathna T, McCarthy JS, Davis TM (2007) Common infections in diabetes: Pathogenesis, management and relationship to glycaemic control. Diabetes Metab Res Rev 23: 3-13.

3. American Diabetes Association (2014) Diagnosis and classification of diabetes mellitus. Diabetes care 37: S81-S90.

4. Wiwanitkit V (2011) Outbreak of Escherichia coli and diabetes mellitus. Indian J Endocrinol Metab 15: S70-S71.

5. Leslie RD, Kolb H, Schloot NC, Buzzetti R, Mauricio D, et al. (2008) Diabetes classification: Grey zones, sound and smoke: Action LADA 1. Diabetes Metab Res Rev 24: 511 519.

6. Johnsson KM, Ptaszynska A, Schmitz B, Sugg J, Parikh SJ, et al. (2013) Urinary tract infections in patients with diabetes treated with dapagliflozin J Diabetes Complications 27: 473-478.

7. Butler SO, Btaiche IF, Alaniz C (2005) Relationship between hyperglycemia and infection in critically ill patients. Pharmacotherapy. Pharmacotherapy 25: 963-976.

8. Geerlings SE, Hoepelman Al (1999) Immune dysfunction in patients with diabetes mellitus (DM). FEMS Immunol Med Microbiol 26: 259-265.

9. Plotkin BJ, Viselli SM (2000) Effect of insulin on microbial growth. Curr Microbiol 41: 60-64.

10. Plotkin BJ, Wu Z, Ward K, Nadella S, Green JM, et al (2014) Effect of human insulin on the formation of catheterassociated E. coli biofilms. Open Journal of Urology 4: 4956.
11. Klosowska K, Plotkin B (2006) Human insulin modulation of Escherichia coli adherence and chemotaxis. American Journal of Infectious Diseases 2: 197-200.

12. Christensen GD, Simpson WA, Bisno AL, Beachey $\mathrm{EH}$ (1982) Adherence of slime-producing strains of Staphylococcus epidermidis to smooth surfaces. Infect Immun 37: 318-326.

13. Culp E, Wright GD (2017) Bacterial proteases, untapped antimicrobial drug targets. J Antibiot 70: 366-377.

14. Banu A, Hassan MM, Rajkumar J, Srinivasa S (2015) Spectrum of bacteria associated with diabetic foot ulcer and biofilm formation: A prospective study. Australas Med J 8: 280-285.

15. Harwalkar A, Gupta S, Rao A, Srinivasa H(2015) Prevalence of virulence factors and phylogenetic characterization of uropathogenic Escherichia coli causing urinary tract infection in patients with and without diabetes mellitus. Trans R Soc Trop Med Hyg 109: 769-774.

16. Rutherford ST, Bassler BL (2012) Bacterial quorum sensing: Its role in virulence and possibilities for its control. Cold Spring Harb Perspect Med 2.

17. Delcaru C, Alexandru I, Podgoreanu P, Grosu M, Stavropoulos E, et al. (2016 ) Microbial biofilms in urinary tract infections and prostatitis: etiology, pathogenicity, and combating strategies. Pathogens 5: 65.

18. Waldrop R, McLaren A, Calara F, McLemore R (2014) Biofilm growth has a threshold response to glucose in vitro. Clin Orthop Relat Res 472: 3305-3310.

19. Peleg AY, Hooper DC (2010) Hospital-acquired infections due to gram-negative bacteria. N Engl J Med 362: 1804-1813.

20. Toval F, Köhler CD, Vogel U, Wagenlehner F, Mellmann A, et al. (2014) Characterization of Escherichia coli isolates from hospital inpatients or outpatients with urinary tract infection. J Clin Microbiol 52: 407-418. 